\section{SEMIOTICA DAS EXPRESSÕES MARCÁRIAS: NOMES, MASCOTES, SÍMBOLOS, LOGOTIPOS E PUBLICIDADE EM ANÁLISE}

A primeira edição de 2017 da Signos do Consumo oferece um conjunto de reflexões que transitam pela teoria peirceana às reflexões psicossociológicas, colocando em análise distintas perspectivas de marcas e publicidade comerciais e governamentais. Ao todo, são nove artigos, praticamente todos decorrentes de pesquisas que vão ao encontro da Comunicação e do Consumo de diversas regiões do país e de instituições das mais variadas. Essa seleção, uma vez mais, reforça nosso compromisso com o espaço da diversidade e da abrangência nacional das investigações na área.

Nessa perspectiva pluralista, apresentamos o artigo "Deslizando pelas categorias sígnicas de C. S. Peirce: um estudo de caso”, de Priscila Borges, professora da Universidade de Brasília, e Marcelo Santos, professor da Faculdade Casper Líbero. Os autores oferecem a análise semiótica da marca de refrigerantes $\mathrm{H} 2 \mathrm{OH}$ !, de propriedade da Ambev, aplicando a Teoria Geral dos Signos de Peirce, que contribui para a já tradicional área de análise semiótica das manifestações de marca.

"Dez vezes sem juros: uma análise dos mecanismos de persuasão utilizados na publicidade de varejo" é o texto de autoria de José Maria Melim, da Universidade Sociedade Educacional de Santa Catarina (UniSociesc), e Maurício José Melim, da Associação Luterana Bom Jesus (Ielusc) de Santa Catarina. Os autores apresentam um ensaio analítico sobre a persuasão na publicidade, com arcabouço teórico multidisciplinar que integra conceitos de psicologia social e semiótica. O foco da análise é um típico anúncio de varejo, em que os autores buscam identificar a presença de certos mecanismos psicológicos de persuasão, para em seguida descreverem o modo como tais mecanismos estão materializados sob a forma de signos figurativos, linguísticos e plásticos. É também uma contribuição muito relevante aos estudos da persuasão publicitária em uma perspectiva que integra semiótica e psicologia como fundamentos teóricos.

O pesquisador Ramon Bezerra Costa, professor da Universidade Federal do Maranhão (UFMA), contribui para esta edição com o artigo "Comunicação e consumo: sobre a produção de modos de vida no Airbnb”, que nos oferece consistente reflexão sobre a marca e o negócio Airbnb, um site que permite alugar a própria residência, estando ou não nela, para pessoas desconhecidas. Sua fundamentação está na oferta e na comercialização pela internet, evidenciando lógicas de organização que sugerem distender as fronteiras entre a vida pública e a privada, além de conformar genuínos processos de construção da confiança entre desconhecidos, o que em primeira abordagem parece difícil. Esse novo negócio, que também impõe novas formas relacionais, é abordado na perspectiva da Comunicação e do Consumo, entendidos como processo de vinculação social e produção de modos de vida, mediados por tecnologias digitais.

Dora Carvalho, da Escola Superior de Propaganda e Marketing (ESPM), apresenta suas reflexões sobre as novas formas de consumo de livros no artigo "Booktrailers: novas formas de consumir livros e micronarrativas que 
capturam o leitor”. Os booktrailers são atualmente uma das estratégias de divulgação de lançamentos literários tanto no mercado mundial quanto no brasileiro e visam atrair o leitor para as tramas apresentadas nas novas obras utilizando conceitos e práticas tão distintos quanto bricolagem, ready-made, gêneros discursivos clássicos da publicidade, narrativas e explorações da memória. Nesse contexto, o estudo propõe uma discussão sobre formas utilizadas por publicitários para persuadir e encantar seus leitores, levando-os a consumir novos livros, objetivo fim da estratégia.

A professora da Fundação "Armando Alvares Penteado" (FAAP) Andrea Mello apresenta uma análise da mascote Pinguim da marca varejista Ponto Frio, utilizando o método semiótico de Charles Peirce aplicado ao contexto do ambiente digital, uma vez que, na origem, a mascote nasce nesse cenário. A opção recaiu sobre o ambiente do Twitter - rede social com mais de 300 milhões de usuários no mundo - e o foco da análise está na busca da identificação de estratégias de manifestação marcária mais rentáveis ao contexto do varejo brasileiro.

Alana Giro Jorge, da Escola de Comunicação e Artes (ECA) da Universidade de São Paulo (USP), apresenta o texto "Comunicação do Governo Federal e identidade brasileira: análise das logomarcas dos governos Lula e Dilma”. O artigo procura entender, por meio da semiótica aplicada, o universo de sentido e os traços identitários brasileiros empregados nas principais comunicações institucionais do Governo Federal. Ao analisar os logotipos e símbolos dos Governos Lula e Dilma, a autora observa a grande diferença entre os signos empregados. Enquanto o governo do presidente Lula colocava em destaque a miscigenação do povo brasileiro, no período Dilma, o tema da desigualdade social e a estabilidade e força do Estado passam a ser o foco. Aqui, fica evidente que uma análise semiótica das expressões marcárias é capaz de manifestar o posicionamento estratégico e ideológico dos respectivos governos analisados. É uma contribuição importante aos estudos do potencial comunicativo das marcas no contexto público e político.

As pesquisadoras gaúchas Fárida Rabuske Kuntz, da Universidade Federal de Santa Maria (UFSM), e Elisa Reinhardt Piedras, da Universidade Federal do Rio Grande do Sul (UFRGS), apresentam o artigo “Algumas coisas não são muito verdadeiras’: consumo midiático e recepção da publicidade televisiva na infância”, seguindo os tradicionais estudos midiáticos da região Sul do país. O estudo tem o objetivo de explorar os hábitos de consumo de televisão e, mais especificamente, a recepção da publicidade dirigida à criança. Após discussão teórica sobre publicidade, recepção e infância, operacionalizam metodologicamente a noção de fluxo publicitário em pesquisa exploratória e qualitativa, realizada por meio de entrevistas com seis crianças. Os resultados revelam hábitos de consumo e práticas de recepção da publicidade televisiva.

Os pesquisadores do Núcleo de Pesquisas em Comunicação e Censura (NPCC) Ivan Paganotti e Mariana de Toledo Marchesi oferecem o texto "Selos e apelos: fabricação da imagem de açúcar 'verde' e agendamento”. O objetivo da reflexão dos autores é analisar a construção da imagem de marcas sustentáveis de açúcar a partir das informações e representações imagéticas utilizadas nas embalagens desses produtos destinadas aos consumidores. A representação da consciência socioambiental diverge entre as empresas avaliadas: União, Native e Guarani. Os autores concluem que tais diferenças se baseiam em estratégias divergentes 
de agendamento dos comportamentos dos consumidores e só União e Native fundamentam sua imagem em selos e certificados de instituições que avaliam a gestão sustentável dos produtos. Esses selos conferem credibilidade, aliando perspectiva estética (selo-embalagem) à ética (realmente "verdes", pelo endosso).

Três pesquisadoras da Universidade Federal de Viçosa (UFV) apresentam o artigo "O consumo dos serviços de crédito por idosos do Programa Municipal de Terceira Idade de Viçosa, Minas Gerais”. Adriana Vasconcelos, Neuza Maria da Silva e Marcia Barroso Fontes analisam as diferentes formas como ocorrem o consumo dos serviços de crédito, verificando valores contratados a título de crédito consignado, limite do cartão de crédito e do crediário, por meio de pesquisa quantitativa com cinquenta e dois idosos participantes de um Programa de Terceira Idade do Município de Viçosa, Minas Gerais. As autoras verificaram importante autonomia desse público ao que se refere à contratação do crédito, como também à necessidade constante de recorrer a esse tipo de serviço por razões diversas. Vale conferir. O estudo se insere nas pesquisas que integram as investigações sobre periodização da vida e consumo, bastante destacadas nos últimos anos nas preocupações do Departamento de Relações Públicas, Propaganda e Turismo (CRP) e do Programa de Pós-Graduação em Ciências da Comunicação (PPGCOM) da ECA-USP.

Para finalizar esta edição da Signos do Consumo, Pablo Moreno Fernandes Viana, professor da Pontifícia Universidade Católica (PUC) de Minas Gerais e pesquisador do Grupo de Estudos Semióticos em Comunicação, Cultura e Consumo (GESC3), apresenta a resenha do livro Da hibridização à regionalização: a publicidade contemporânea, de Rogério Covaleski, síntese integradora de suas pesquisas, anteriormente publicadas em outros dois livros.

Desejamos uma ótima leitura. Até a próxima edição.

Clotilde Perez e Eneus Trindade Editores 